\title{
Goal gradient effect of incentive motivation (K) manipulated through prior goal box placements'
}

PETER C. SENKOWSKI ${ }^{2}$, JOHN J. PORTER AND HARRY L. MADISON, DEPARTMENT OF PSYCHOLOGY, UNIVERSITY OF WISCONSIN, Milwaukee, Wis. 53201

Four groups of 12 rats were run in a straight alley to test Spence's (1956) hypothesis that incentive motivation $(K)$ can be developed prior to the learning of a running response. The $S s$ received either 10 or 60 goal box (GB) placements, either rewarded or nonrewarded, prior to running trials. First trial running performance of the $60 G B$ rewarded group was superior to the other groups, especially on running measures taken nearest the $G B$. This superiority was maintained over the 10 acquisition trials, again mostly near the GB. The results supported Spence's hypothesis, and the concept of generalization of $r_{g}-s_{g}$ backwards from the $G B$.

According to Spence (1956), instrumental reward performance involves the formation of two habits, the instrumental conditioned response leading to the reinforcer, and the consummatory response $\left(R_{g}\right)$ with its fractional component $\left(r_{g}\right)$ which becomes classically conditioned to the stimuli of the instrumental situation. This second habit provides the mechanism underlying the incentive motivation factor $(\mathrm{K})$. Response speed in instrumental reward performance is a function of both habit strength $(\mathrm{H})$ and $\mathrm{K}$, where $\mathrm{H}$ depends upon the number of training trials while $\mathrm{K}$ depends upon the magnitude of the reward and the number of $\mathrm{Rg}$ 's. Since the number of $\mathrm{R}_{\mathrm{g}}$ trials, and thus $\mathrm{K}$, can be varied independently of the instrumental response, $K$ can be varied without varying $H$. If $K$ has developed before Ss begin runway trials, via previous $R_{g}$ training, such $S s$ should run faster than $S s$ without prior $R_{g}$ training. Specifically, if a goal box (GB) is similar to the runway proper, repeated rewarded GB placements should produce $\mathrm{rg}$ 's which will be reflected in $\mathrm{K}$, and hence facilitate first trial runway performance.

Several investigators (Stein, 1957; Swift \& Wike, 1958; Gonzalez \& Diamond, 1960) have attempted to test this hypothesis, mostly with negative results. It is possible that the number of prior rewarded placements, ranging from nine to 51 in these studies, was not sufficient to produce an adequate value of $K$. It is also possible, and of more theoretical interest, that the measures of performance did not adequately reflect behavior in the later parts of the runway, where the generalization of $r_{g}$ should be most pronounced.

The present experiment tested the hypothesis that (a) the effect of $\mathrm{K}$ upon first trial runway performance is dependent upon the number of prior GB placements, and that (b) the effect of prior placements should be most evident near the goal. Accordingly, Ss given 60 rewarded GB placements should run faster than Ss given only 10 rewarded placements, especially near the goal. To control for the possibility that the hypothesized superior performance following the larger number of rewarded GB placements could be due to some factor other than the effect of $R_{g}$ training, control groups receiving either 10 or 60 nonrewarded GB placements were also run. Since $\mathrm{K}$ should not increase as a function of nonrewarded GB placements, no difference in performance should occur between Ss given different numbers of nonrewarded GB placements, and running performance after rewarded GB placements should be superior to performance without such treatment.

Method. The Ss were 48 experimentally naive, male albino rats of the Holtzman strain, 120-150 days old at the start of the experiment. The apparatus was a $5 \mathrm{ft}$ runway, with a $1 \mathrm{ft}$ start box and a $1 \frac{1}{2} \mathrm{ft} \mathrm{GB}$. The start box and runway proper were $3 \mathrm{in}$. wide, and the $\mathrm{GB}$ was $4 \frac{1}{2} \mathrm{in}$. wide. Photocell relays were used for three response measures: Start time from the opening of the start box to $1 \mathrm{ft}$ into the runway, alley time from $1 \mathrm{ft}$ into the runway to GB entry, and GB time from GB entry to the food cup located $1:$ in. from the far end of the GB. All measures were converted to specd by taking reciprocals.
All Ss were given 10 min exploration of the entire runway on Day 1, and two nonrewarded runway trials on Day 2. All Ss were grouped according to mean running speed on Day 2, and randomly assigned within running speed levels to four treatment groups of $12 \mathrm{Ss}$ each. They were then maintained at $23 \mathrm{~h}$ food deprivation at the start of each experimental session. Pretraining began on Day 9 for half the Ss, Group 60R receiving 10 rewarded GB placements per day for six days, while given $15 \mathrm{sec}$ to consume two $97 \mathrm{mg}$ Noyes pellets. Group 60NR was given 60 nonrewarded GB placements of 15 sec each, receiving the same reward after a delay of $5 \mathrm{~min}$ in a carrying cage. A minimum of 5 min elapsed between feeding and the next GB placement. On Day 14, Groups 10R and 10NR received 10 rewarded and nonrewarded GB placements, respectively, following the same procedures.

On Day 15, each $S$ received 10 acquisition trials in the runway, rewarded with two $97 \mathrm{mg}$ pellets per trial, with an intertrial interval of $10 \mathrm{~min}$. The $S$ was placed in the start box and 5 sec later the door was opened. The start box and $\mathrm{GB}$ doors were closed after $\mathrm{S}$ to prevent retracing, and $\mathrm{S}$ was removed to his carrying cage immediately after consuming the reward. Thus, all Ss were treated the same during acquisition.

Results and Discussion. The mean running speeds for each response measure are shown in Table 1. Our primary concern was with the performance on Trial 1 , the first runway trial. To determine the effect of number of prior GB placements upon running speed, comparisons were made between Groups 60NR and $10 \mathrm{NR}$, and between Groups 60R and 10R. As hypothesized, Groups 60NR and 10NR did not differ significantly on Trial 1 for any of the measures. Groups $60 \mathrm{R}$ and $10 \mathrm{R}$ did not differ significantly in start speed, but Group $60 \mathrm{R}$ was significantly faster in alley speed $(\mathrm{t}=2.30, \mathrm{df}=22, \mathrm{p}<.05)$ and even more so in $\mathrm{GB}$ speed $(\mathrm{t}=3.28, \mathrm{df}=22, \mathrm{p}<.01)$ as predictea from the hypothesis that the effect of prior rewarded GB placements should be evidenced most near the goal.

The effect of prior rewarded GB placements was further examined by analysis of the difference between mean performance on the two pretraining, or baseline trials, and on Trial 1. As can be seen in Table 1, Ss in Group $60 \mathrm{R}$ were significantly faster on Trial 1 GB speed $(t=3.08, \mathrm{df}=11, \mathrm{p}<.05)$ than on the same measure during pretraining. This was also true for Group 10R $(t=2.73, \mathrm{df}$ $=11, \mathrm{p}<.05$ ), but not for Groups 60NR or 10NR, which did not show significant increases in speed. The alley speed measure yielded similar results, with the Trial 1 speeds being faster in Group 60R $(\mathrm{t}=2.63$, $\mathrm{df}=11, \mathrm{p}<.05)$, and approaching significant differences between baseline and Trial 1 speed at the .05 level for Group 10R. The differences were not significant for Groups $60 \mathrm{NR}$ or 10NR. The start speed measure failed to show significantly faster running on Trial 1 compared to the baseline for any group. Again, the effect of prior rewarded GB placements was evidenced most near the goal.

Although no specific comparisons were dictated by our hypothesis, the data for all 10 acquisition trials were examined. The effects of 60 vs $10 \mathrm{~GB}$ placements, and rewarded vs nonrewarded placements upon GB speed were significant $(F=7.81$ and 38.8 , respectively, $\mathrm{df}=1 / 44, \mathrm{p}<.01)$. The $\mathrm{GB}$ speed also increased over trials $(F=28.05$, df $=9 / 396, p<.01)$, and there was also a

Table 1

Mean Response Speeds in Pretraining. Trial 1, and for all 10 Acquisition Trials

\begin{tabular}{|c|c|c|c|c|c|c|c|c|c|}
\hline \multirow[b]{2}{*}{ Group } & \multicolumn{3}{|c|}{ Pretraining } & \multicolumn{3}{|c|}{ Trial 1} & \multicolumn{3}{|c|}{ Trials $1-10$} \\
\hline & Start & Alley & GB & Start & Alley & $\mathrm{GB}$ & Start & Alley & GB \\
\hline $60 \mathrm{R}$ & .619 & .112 & .332 & .724 & .159 & .704 & 1.980 & .393 & 1.217 \\
\hline $60 \mathrm{NR}$ & .617 & .114 & .108 & .315 & .094 & .253 & 1.600 & .288 & .676 \\
\hline $10 \mathrm{R}$ & .438 & .069 & .295 & .430 & .113 & .357 & 1.546 & .326 & .877 \\
\hline 10NR & .498 & .097 & .340 & .498 & .122 & .366 & 1.590 & .285 & .689 \\
\hline
\end{tabular}


significant interaction between number of $\mathrm{GB}$ placements and whether the placements were rewarded $(F=9.14$, df $=1 / 44, p<$ $.01)$, due mainly to the superiority of Group 60R over Group $60 \mathrm{NR}(\mathrm{F}=21.4, \mathrm{df}=1 / 44, \mathrm{p}<.01)$. For alley speed, number of GB placements had no significant effect, but place of reward did, with Ss rewarded in the GB running faster than those fed later in the carrying cage $(F=14.81, \mathrm{df}=1 / 44, \mathrm{p}<.01)$. The trials effect was significant $(F=161.7, \mathrm{df}=9 / 396, \mathrm{p}<.001)$, and a place of reward by trials interaction $(F=4.33$, df $=9 / 396, p<.01)$, was due to the more rapid acquisition of the $G B$ rewarded groups. Start speeds increased over trials $(F=16.52$, df $=9 / 396, p<.01)$, but did not show significant effects due to number of GB placements, or place of reward. Once again, the effects of rewarded GB placements were most evident in measures taken nearer the goal.

These data confirm that prior rewarded GB placements facilitate first trial runway performance and lend support to Spence's (1956) hypothesis concerning the action of $r_{g}$ upon running performance. The effect of prior rewarded GB placements was progressively less apparent as measures were taken further from the goal. This is in agreement with Spence's hypothesis concerning the generalization of $r_{g}$, which presumes that the conditioning of $\mathrm{r}_{\mathrm{g}}$ progresses backward from the GB through stimulus generalization.

\section{REFERENCES}

GONZALEZ, R. C., \& DIAMOND, L. A test of Spence's theory of incentive motivation. Amer. J. Psychol, 1960, 73, 396-403.

SPENCE, K. W. Behavior theory and conditioning. New Haven: Yale U. Press, 1956.

STEIN, L. The classical conditioning of the consummatory response as a determinant of instrumental performance. J. comp. physiol. Psychol, 1957, 50, 269-278.

SWIFT, C. F., \& WIKE, E. L. A test of Spence's theory of incentive motivation. Psychol. Rec., 1958, 8, 21-25.

\section{NOTES}

1. This investigation is based upon the first author's M.S. Thesis under the direction of the second author. The research was supported by NSF Grant GB-3466 to the second author.

2. Now at the University of Iowa. 